Revista de LA Escuela de Ciencias de LA EdUUCACIÓn, AÑo 12, NRO. 11, vol. 2, JULIO A diciembre de 2016. PÁGINAS 245-247. ISSN 1851-6297. ISSN 2362-3349 (EN LINEA). EFEMÉRIDES: UNA OPORTUNIDAD PARA PENSAR LA VIDA COMÚN. MARÍA INÉS MONZÓN

\title{
“EFEMÉRIDES: UNA OPORTUNIDAD PARA PENSAR LA VIDA COMÚN"
}

\author{
María Inés Monzón* \\ Universidad de Entre Ríos, Argentina. \\ mimonzon@live.com
}

"Efemérides: una oportunidad para pensar la vida común"

Por Nicolás Arata con investigación y elaboración de recursos didácticos a cargo de Gabriela Carnevale - Ciudad Autónoma de Buenos Aires: Editorial Mandioca. 2014.

Cuando un investigador tiene la intencionalidad de poner a disposición unas reflexiones para pensar la vida en común en los contextos escolares se encuentra al menos ante dos desafíos, por un lado, dejarse interpelar por las voces docentes que cotidianamente los habitan y construyen aquello de lo "común" a partir de sus propuestas de enseñanza y, por otro, ser respetuoso en la lectura de sus prácticas de enseñanza habilitando espacios de intercambio, reflexión y proposición colectivos.

Ambos desafíos atraviesan la escritura del libro "Efemérides: Una oportunidad para pensar la vida en común" de Nicolás Arata con investigación y elaboración de recursos didácticos a cargo de Gabriela Carnevale, publicado por Editorial Mandioca en 2014.

El libro está escrito en un leguaje coloquial, sin que ello quite su rigurosidad y pertinencia académica, dirigido principalmente a docentes como también a cualquier lector que se interese por el tema. Está organizado en tres secciones, una presentación a modo de consideraciones iniciales sobre la intencionalidad de su escritura; un desarrollo de distintas secuencias de enseñanza para el abordaje de diferentes efemérides escolares que, desde una noción ampliada, rememoran fechas que representan para sus autores acontecimientos que se inscriben en un horizonte de problemas comunes

* Profesora en Ciencias de la Educación, egresada de la Facultad de Ciencias de la Educación de la Universidad Nacional de Entre Ríos, y Doctoranda de la tercera cohorte del Doctorado en Educación, dictado en dicha casa de estudios. 
Revista de la Escuela de Ciencias de la Edducación, año 12, nRo. 11, vol. 2, JULIO A diciembre de 2016. PÁGINAs 245-247. ISSN 1851-6297. ISSN 2362-3349 (EN LINEA). EFEMÉRIDES: UNA OPORTUNIDAD PARA PENSAR LA VIDA COMÚN. MARÍA INÉS MONZÓN

sobre lo que la escuela tiene algo para decir y, un último apartado, referido a bibliografía ampliada para ampliar las consultas. Cabe aclarar que no se especifica la situacionalidad de las propuestas, es decir no se plantea el nivel escolar para el que se plantean las situaciones de enseñanza propuestas para el abordaje de las efemérides delimitadas, pero como se advierte en su presentación las clases planificadas no se presentan a modo de "recetas" a aplicar, sino suponen la ocasión para invitar a que cada docente las recree, problematice y reinvente en sus propias prácticas de enseñanza.

Considero que este punto anteriormente planteado es la característica más significativa del libro, ya que las propuestas de enseñanza presentadas intentan conmover la capacidad de experimentar y desordenar el archivo cultural por parte de los docentes en su acto, siempre político, de enseñar a otros -estudiantes- herederos de nuestra historia nacional. Una herencia que en el acto de enseñar no se distingue por su repetición sino por la posibilidad de que los otros hagan con ella el mejor de los inventos posibles, en este caso, nuevos modos de habitar y vivir juntos.

En tal sentido las efemérides que se recuperan refieren a acontecimientos históricos, políticos y socioculturales que, si bien, no han sido soslayados en el "tratamiento escolar" son recuperados en este libro desde una mirada puesta en los efectos que en su transmisión escolar nos habilitan, tanto a docentes como a estudiantes, a problematizar sobre nuestro presente: 8 de marzo Mujeres; 24 de marzo Memoria con Verdad y Justicia; 2 de abril Tras un manto de consignas; $1^{\circ}$ de mayo Los trabajos y los días; 25 de mayo El Taller de la Nacionalidad; 5 de junio SUMAK KAWSAY; 15 de junio Todos los libros, El libro; 20 de junio Preguntas de un alumno lector, 9 de julio Nos: La Independencia; 7 de agosto Educación y Religión: imaginar un diálogo; 17 de agosto Un ejército de ideas; 11 de septiembre Sombra terrible de Sarmiento; 12 de octubre Nuestra América y; 20 de noviembre Las vueltas de la Soberanía.

En su desarrollo, al proponerse la secuencia didáctica para estos distintos acontecimientos se comienza con un texto a modo de "ensayo de reflexión" sobre el tema a enseñar, una escritura que sus autores pretenden disponer a modo de apuntes de clase que ofician de disparador para el diálogo.

A partir de la lectura de las distintas propuestas de enseñanza considero que estos apuntes de reflexión pueden ser recuperados en dos sentidos, como textos a ser trabajados con los estudiantes o como escrituras que se proponen como disparadores para que los docentes construyamos nuestros propios ensayos y/o textos de saber para la enseñanza del tema. En este punto es en el que vuelvo a plantear lo que, desde mi punto de vista, supone la riqueza de este libro: la invitación a que los docentes revisitemos nuestros modos de relación de y con el saber de la historia y, en tal sentido, de nuestra herencia cultural. En otras palabras nos plantea el desafío como docentes de 
Revista de la Escuela de Ciencias de la Edducación, AÑo 12, nRo. 11, vol. 2, JULIO A diciembre de 2016. PÁGINAs 245-247. ISSN 1851-6297. ISSN 2362-3349 (EN LINEA). EFEMÉRIDES: UNA OPORTUNIDAD PARA PENSAR LA VIDA COMÚN. MARÍA INÉS MONZÓN

repensar que, los modos en que nos relacionamos con el conocimiento a ser enseñado en los contextos escolares siempre se vinculan con los modos en que construimos singularmente nuestra relación con el saber, en este caso, el histórico.

En este marco, considero que todos los lectores (principalmente las/os docentes) que se interesen por su lectura deben partir de la premisa de que el mismo es un espacio para conversar sobre aquello que construimos y significamos sobre lo común a la hora de posicionarnos con trasmisores de una cultura nacional.

En suma, considero que este libro se presenta como la ocasión de problematizar nuestro archivo cultural, en tanto que el archivo - en términos foucaultianos- no se refiere al conjunto de documentos que una cultura guarda como memoria y testimonio de su pasado sino como el sistema de las condiciones históricas de posibilidad de los enunciados, en este caso, los enunciados que subyacen a nuestros modos de trasmitir y construir lo común en los escenarios escolares. 